\title{
BIM-GIS INTEGRATION FOR TRAFFIC SAFETY IN CITIES
}

\author{
Mohamed El Mekawy ${ }^{1}$, Mutasim Issa $^{2}$, Erik Perjons ${ }^{1}$ \\ ${ }^{1}$ Stockholm University, Sweden \\ ${ }^{2}$ Sourcya Company, Sweden-Egypt
}

KEY WORDS: BIM, GIS, BIM-GIS Integration, RTPS, UBM, Traffic Safety, GCITY.

\begin{abstract}
:
This paper reports on the results and further extensions of a concept project that was financially supported by VINNOVA (Sweden's innovation agency). The project aims, by integrating BIM and GIS, to support traffic safety and contribute towards decreasing the probability of car accidents in general and car-bicycle in more specific. The main objective of the project was to investigate different technologies that support the out- and indoor navigation of moving objects on building and geospatial city models based on BIM and GIS, and to present real life objects which help traffic users in taking better decisions. The concept study had a consortium of six partners (academic and industrial). The project resulted in a proposed solution to be implemented in the ongoing extension of the same project. The proposed solution is argued to be comprehensive that utilises BIM-GIS integration, their capabilities and Real Time Positioning Services (RTPS) for smart cities' applications. Beside its scientific impact, it can be strongly argued that the proposed solution has a high potential for social-economic impact in creating the awareness and framework for automotive, lightweight vehicles manufacturers and automotive appliances suppliers to collaborate in facing this type of rising traffic problem. In addition to that, the open-source nature of the project will encourage different industrial parties to participate and re-utilize the project's deliverables in new methods and ideas.
\end{abstract}

\section{INTRODUCTION}

Digital societies today are largely dependent on information. However, several tasks in urban and architectural design are today undertaken in a geospatial context. Building Information Models (BIM) and geospatial technologies offer 3D city models that provide information about buildings and the surrounding environment (Hijazi et al. 2018). A 3D city model is generally defined as the digital representation of the Earth's surface and the built environment within a city. Using such a model, a variety of applications may be created, covering the whole city or a focused specific building model. As the models become more detailed, the relationships between the spatial objects have to be modelled (Stadler and Kolbe, 2007).

The recent development in technology, especially in restoring and storage of data, has brought several advantages to build more detailed city models and use them in different applications. As a result, the two domains, BIM and GIS, are moving closer to each other towards easier integration and interoperability process between them (Wang et al., 2019). The BIM-GIS integration provides a unified view of geospatial information and is seen as future development of urban planning and smart cities' applications (Song et al., 2017)

As a result of increasing demands on integrated views and data standards in urban planning, unified applications have received great attention at both national and international levels. At the EU level, different initiatives, such as the Infrastructure for Spatial Information in the European Community (INSPIRE) directive (European Commission - INSPIRE, 2007-2021), have suggested building common geospatial applications for EU countries based on BIM-GIS integration. This has contributed to different smart cities application in the functions of smart planning, end-to-end solutions, services, management, sustainable practices, and outcomes/policy making, emergency, security and others. The geospatial structure in a smart city ecosystem, can serve any or all of the above functions. For instance, Hamburg, Germany, implements GIS in a smart energy-efficient housing initiative, while Stockholm, Sweden, focuses on smart e-services.

\subsection{Research Problem}

Sweden is one of the best performing European countries in road safety (Swedish Transport Agency, 2021). However, unprotected road users are still having a high percentage in injury-hit groups. The percentage of the traffic fatalities has fallen down, according to the Swedish Transport Analysis (2020), only from $44 \%$ in 2016 to $40 \%$ in 2019 of those who were involved in automobile collision, although the number of total fatalities has fallen down by $18 \%$ between the two years from 270 to 221 . In the same time, the percentage of seriously injured cyclists of total injured persons increased from $41 \%$ in 2016 to $49 \%$ in 2019 .

According to the Swedish Transport Agency (2017), accidents between heavy vehicles and cyclists is a major problem in many Swedish cities. The cause of accidents is often related to that the driver of a heavy vehicle does not detect the cyclist. Several large cities such as London and Copenhagen look at instituting special demands on trucks such as stricter term requirements but no any requirements for detecting systems. Buses as well as the public transportation in general are today encouraged more than any time before. In addition to that, the transport policy objective inside the cities is motivated towards increasing the travel by bicycle for more sustainable transport and reducing the environmental impact. We can thus expect more potential conflicts between heavy vehicles and bicycles, thus increasing road safety problems. But the overall goal of the traffic committee was clearly expressed in January 2015 to focus on the safety of cyclists.

The safety of unprotected road users has attracted an increased interest of researchers and industry actors at both national and international levels. These interests were put into projects by the automobile manufacturers to develop systems or solutions for 
reducing the cyclists and motor vehicle collisions. Examples of these projects are: i) an active system (in Jaguar Land Rover) that alerts car drivers to unseen dangers and hazards. The system is expected to distinguish between bicycle and motorcycles using a range of "instinctive stimuli" to warn a driver of approaching danger (Jaguar Land Rover, 2021), ii) signalling system (in Mercedes Benz) for cyclists on safe passage zone in front of the car. The system is mainly based on radar sensor that monitors the entire area next to the automobile/truck (Mercedez-Benz, 2021; Daimler, 2021), iii) anti-collision warning system for bicycles in Volvo cars. The car's brakes is automatically activated when the car and cyclist are in danger of colliding (Volvo, 2021).

At the research level, a record number of participants was achieved in the 3rd International Cycling Safety Conference (ICSC2014) in Gothenburg City, November 2014. Not only theories, but that conference was a turning point for highlighting different initiatives by research teams, authorities and industries from 23 different countries to start thinking of bicycle, scooter and similar light-weight vehicles as a strong transport alternative in the 21 st century's cities. This has continued in the two following conferences in Hannover (Germany) and Bologna (Italy) for the years 2015 and 2016 respectively. It has become a well-established and specialised conference with its latest conference that will be held in November 2021. In additional to that, several research projects are currently ongoing for improving or contributing to the reduction of car-bike collision. Among these projects is the Vinnova-funded project (Cyclist Collision Avoidance Using Imagery Sensor, started Sep 2016) which aims at developing reliable and robust algorithms for a car-integrated camera system that can detect bicycle and cyclist. In top of that, a global policy was made in Horizon 2020 agenda for unprotected road users in the call for proposals in 2014, and as a strategic goal for smart cities. (Horizon 2020, 2021).

However, most of automotive research efforts are mainly yet relying on visualization-based technology mounted on the vehicles whether they are cameras or radar systems. They provide signals or warning voice messages to the car drivers when they come within a proximity of another vehicle.

The shortcomings in these solutions can be summarised as:

- the sensors or cameras cannot "see" the moving objects that are hidden behind other physical obstacles or hinders.

- the sensors and cameras do not "understand" the traffic directions and lanes. Therefore, a nearby moving object might not be in a danger mood (if it is on the opposite lane but separated by a physical hinder), however, the sensor or the camera highlights it. This might cause an incorrect focus for the driver.

- the sensors and cameras are weather-dependent (i.e. they do not work efficiently in harsh weather conditions such heavy rain or snow).

- the sensors and cameras are only available to a selection of high-end expensive vehicles.

Our suggested solution, the GCITY project, aims at reducing the probability of accidents between vehicles, by using the capabilities of Geographic Information Systems (GIS), Building Information Modelling (BIM) and Real Time Positioning Services (RTPS). By detecting the object in the real-time with no latency and visualizing it on a GIS map or BIM, the user will have awareness and predictive vision that help to make a better decision.

\section{RELATED WORK ON BIM-GIS INTEGRATION}

A great deal of research is focused on ways for exchanging of information and integrating BIM and GIS together towards a unified 3D city model. Different studies, such as (Fosu et al., 2015; Hijazi and Donaubauer, 2017; Liu et al., 2017; Zhu et al., 2018), have tried to bring these efforts in a systematic literature review, to classify them or to provide a comparative analysis between their approaches. However, we try here to analyse these previous researches and classify them according to their research/application approach:

1) Transforming building models (BIM) into GIS. These research efforts focused more on integrating BIM data in GIS (e.g. Nagel, 2007; El Mekawy et al., 2012b). They have tested their concepts on Industry Foundation Classes (IFC), the open source standard for data model of BIM, and CityGML, the open source standard for data model of GIS. Other researchers (e.g. Isikdag \& Zlatanova, 2009) have worked on generating building models in GIS in lower levels of details (LoDs) using the BIM semantics and the representation of building elements.

2) Transforming/converting GIS to BIM. These efforts focused on different strategies to enrich the GIS models and converting them into BIM. Nagel et al. (2009) have developed a two-step method to extend GIS model (CityGML) by conceptual requirements of BIM elements that are extracted from uninterpreted 3D graphic models. Other researchers (e.g. Van Berlo, 2009; Van Berlo and De Laat, 2011) used Application Domain Extensions (ADE) to define new classes in the GIS open standards (CityGML) and design a framework for presenting building information that is not possible to be presented using the current default classes.

3) Unified Building Model (UBM). El Mekawy et al. (2012a) developed a UBM which is an expressive intermediate meta mode that facilitates the transformation of spatial information from IFC to CityGML and vice versa. It has succeeded to at least highlight an important approach to overcome the limitations of the existing unidirectional approaches. The UBM was also tested for specific use case related to building evacuation by El Mekawy (2012a), and to integrate indoor and outdoor utilities by Hijazi et al. (2012).

4) Semantic Integration. Different research efforts have focused more on the semantic integration or interoperability between BIM and GIS ontologies. Some of these efforts have focused more on the semantic mapping of classes and elements from both BIM and GIS standards (e.g. El Mekawy and Östman, 2010; Hacherouf et al., 2019), while others have focused more on the semantic web technologies to integrate BIM with different geospatial analyses and map their process (e.g. Karan et al., 2016; Hor et al., 2018).

Additional to these efforts, commercial software products and conversion tools have been developed for different directions in the BIM-GIS integration. (IFCExplorer, 2010) and FME (Safe Software, 2010) have been developed mainly the first approach mentioned above where BIM (IFC classes) are transformed to GIS (CityGML classes). Other software focused on the facility management were also developed such as a facility management extension on urban information modelling developed by Mignard \& Nicolle (2014) and a tool on software architecture was developed by Kang and Hong (2015) for BIM-GIS integration in the facility management. 


\section{BACKGROUND TO THE GCITY SOLUTION}

In the last decade, various academic and industrial efforts have successfully integrated, or developed methods for the integration of, BIM and GIS based on one or more approaches of the ones discussed above in Section 1.1. Most of these efforts were actually developed with various applications in mind. This paper reports on the results and further extensions of a concept project that was financially supported by VINNOVA (Sweden's innovation agency). The project aims, by integrating BIM and GIS, to support traffic safety and contribute towards decreasing the probability of car accidents in general and car-bicycle in more specific. The main objective of the project was to investigate different technologies that support the out- and indoor navigation of moving objects on building and geospatial city models based on BIM and GIS, and to present real life objects which help traffic users in taking better decisions.

The project was given a name of GCITY (standing for Geographic Information Systems for Traffic Safety in Cities). The main applicant of the GCITY project is the department of Computer and Systems Sciences, DSV, Stockholm University. There are five other key partners in the project consortium. These are: ESRI Sverige AB, responsible for the GIS part; an SME, responsible for non-GIS development and cloud platforms; Urban ICT Arena, responsible for testing bed and facilitation of different technologies and evaluation, Stockholm City Municipality, providing plans, statistics, BIM, and acting as reference partners; Ericcson, for the $5 \mathrm{G}$ and long-term evolution (LTE).

\subsection{Summary of Concept Project Results}

In the concept study, the project researchers met different parties to discuss different aspects of target technologies. Three partners (DSV-SU, ESSRAA Company and Urban ICT Arena) attended a THING seminar at KTH where leading network solution providers (e.g. Ericsson, Cisco, Telia and others) presented their ideas and solutions. The GCITY project, its idea and solution were discussed with network solution providers during a mingle session. Following that, meetings were done with $5 \mathrm{G}$ and LTE researchers in Ericsson to know more about possibilities of building the solution's network on top of $5 \mathrm{G}$ and/or LTE. Other meetings were organised with ESRI to know more about utilising different technologies (e.g. network analyst and Feature Manipulation Engine (FME)). In the concept study we were able to reach a good assessment regarding different technologies that may help in local positioning, also we knew more about internet of vehicle which is an important topic nowadays and contains standards that manufacturers are already using for applications related to road safety and self-drive cars.

However, the most important deliverable was to produce a comprehensive architecture of the solution with different layers of communication. It was very important to determine which parts of the solution must be powered with real-time capabilities. Related to the architecture, it was important to think about giving the vehicles the ability to communicate with each other on top of inter-vehicle communication protocols.

\section{OVERVIEW OF GCITY SOLUITION}

The GCITY solution will have three main modules. They are: positioning services, vehicle applications and real time cluster. In addition to that, these three modules will communicate and be updated through a GCITY cloud service module.
GCITY depends on the coordinates that comes from GPS or real time positioning systems (RTPS) which will be visualized on GIS map and BIM to give detailed schematic of roads. GPS data will be sent to cloud services which update the map or the model iteratively on the vehicle application to warn the driver before reaching a target crowded traffic area (e.g. intersections).

Data from the RTPS will be sent to RT cluster, attached in a specific location around a target traffic area or intersection. This cluster's module deals more with RT data that deals with local position systems (LPS) based on the FG technology. This provides advantages on both the accuracy and delay time for providing information on the automobile as well as the bicycle side. This cluster connects with the vehicles app/device or the bicycle device, and by using intelligent transportation systems such as Internet of Vehicle (IoV) would make the decision for safer driving.

Data generated from positioning systems will be saved into a relational database to make an approximate use of it in statistics, analyses, metrics, etc. that can be used in the research body by the university, governmental authorities, or institutions.

Positioning Services Module: In this module, the main sources of getting the coordinates of objects will be handled. This is applied by using GPS in the open areas in which high accuracy in nor required, and RT positioning systems APIs in the critical areas in which latency must be avoided. There are a number of technologies in the RT positioning will be studied and tested such as LTE, MPS, UWB, Beacons, etc. Despite the technology used, longitude and latitude will be exported to RT cluster attached around a traffic intersection in order to save it into relational database and resend it to the vehicle app/device or the bicycle device.

GCITY Cloud Services Module: in the cloud services module, there will different services that facilitate the communication and the updates among the other modules and applications:

- GIS/BIM services. In the GCITY solution, Geospatial information system (GIS) and building information modelling (BIM) services allow the positioning and visualization of the moving objects. In GIS, GeoDesign term is used to refer to a scenario-based planning process that applies decision making to spatial problems in the context of local and regional features and characteristics. BIM will help, with an integration with GIS, to focus on the construction details of buildings, roads, and street objects in 2D as well as 3D. By transferring from the GPS to the LPS, the BIM of the focused area, which is pre-saved in the system, will be loaded into the vehicle device. This will allow to increase the detailed information and correspondingly improves its accuracy to centimetres or even millimetres. In addition to that,

Network analyst is used deeply in our solution, as rules and constrains are applied to GIS / BIM layers on roads, intersections and directions. Network analyst tools and relations are used also such as buffer, intersection, etc.

- Application Update. GCITY cloud services provide peripheral application updates that used in locating the objects and visualized moving objects in real time into map layer or BIM model. Application update connects with vehicle application through OTA standard for transmission and reception of application related information in a wireless communication system.

- External APIs Access. GCITY cloud services also provide an external APIs access that allow statistics, analyses, 
reporting, metrics, or any process to enable the university, government, or any research parties to get use of the data saved in the database and integrate more effective solutions or develop the current solution.

- Relational Database. GCITY solution provides a relational database to save the data delivered from the positioning systems, so that it could be used in the access of external APIs. Relational database mainly consists of vehicle ID,
Vehicle Applications Module: this module includes the needed applications for a vehicle to act upon the designed GCITY functions in avoiding collisions among vehicles and bicycles.

- GIS / BIM visualization. This will be a user-friendly interface to visualize GIS maps and BIM. While objects move in the real-time, positioning system obtains the coordinates and vehicle app update the map layer or the BIM model according to the obtained position.

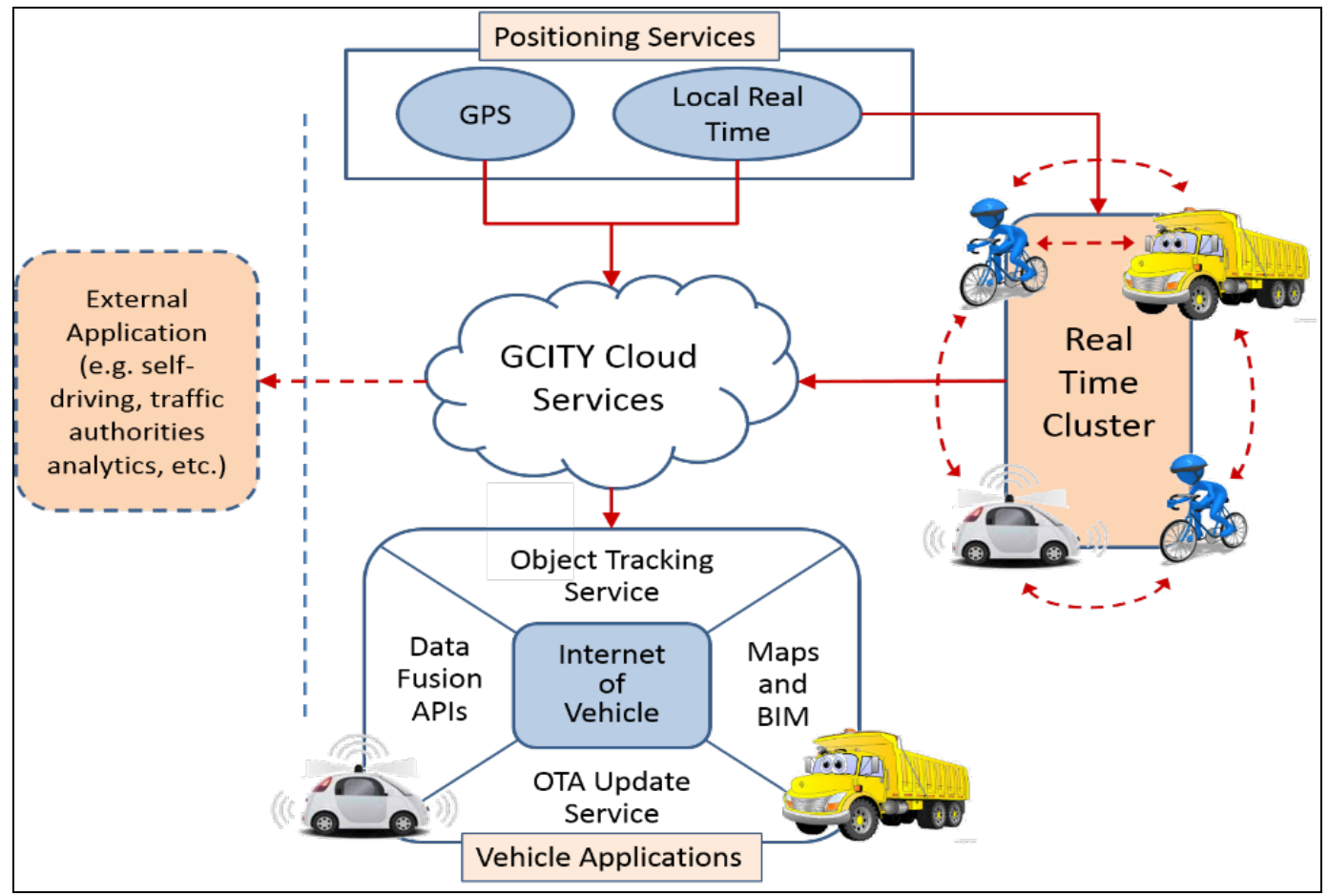

Figure 1. The GCITY Proposed Architecture

longitude, latitude, time and date.

Real Time Cluster Module: This module will be used as a communication platform between the moving objects as well as a peer-to-peer tier between vehicles and bicycles.

- Relational Databases. The X, Y, Z coordinates which are taken from the positioning system, mainly RT positioning systems, will be exported and saved in the RT cluster to save this data in RAM and transmit it to vehicle apps/device and bicycle devices.

- RT APIs. Real Time APIs provide communication between objects in real time communications. Google API is an example of the RT APIs, that allow geocoding and geolocation and the new data is instantly pushed. Esri's mapping API is also an example of the RT API, ESRI's API provide the most powerful mapping visualization, analysis and tools in the real time services. ESRI's API Tracking Server also enables logging and archival of real-time data using the Feature Logger Data Link.

- RT positioning services. Real Time positioning service provides instantly update to the moving objects coordinates in real time, and export data to vehicle applications in a specific format or as a longitude and latitude.
- OTA update services. OTA update services provide a continuous update through transmitting and reception of the application related in a wireless communication system.

- Object tracking services. GCITY vehicle application provide visualization to the moving objects on the road, by drawing a pinpoint on the map or the BIM model. Updated coordinates of the real objects that move on the road are delivered to the vehicle app from GCITY cloud services and also with communication with RT cluster.

- Internet of vehicles. IoV technology refers to dynamic mobile communication systems that communicate between vehicles and public networks using V2V (vehicle-tovehicle), V2R (vehicle-to-road), V2H (vehicle-to-human) and V2S (vehicle-to-sensor) interactions. It enables information sharing and the gathering of information on vehicles, roads and their surrounds. Moreover, it features the processing, computing, sharing and secure release of information onto information platforms. Based on this data, the system can effectively guide and supervise vehicles, and provide abundant multimedia and mobile Internet application services.

- Data Fusion APIs. GCITY solution depends on data fusion to bring sources and information together in an initiative way to make the best use of the big data technology. Data fusion approaches on near-raw sensor data (low-level) and 
on pre-processed measuring points (high-level). GCITY also model sensor phenomena, road traffic scenarios, data fusion paradigms and signal processing algorithms and investigate the impact of combining sensor data on different levels of abstraction on the performance of the multi-sensor system by means of discrete event simulation.

\section{ORIGINALITY AND NEWSWORTHINESS}

The proposed method in GCITY provides a comprehensive solution that utilises BIM-GIS integration for smart cities' applications. The GCITY aims at reducing the probability of accidents between vehicles, by using the capabilities of Geographic Information Systems (GIS), Building Information Modelling (BIM) and Real Time Positioning Services (RTPS). Example: beacons are inexpensive devices that enable accurate locations for indoors by transmitting small amounts of data and utilizes UWB technology) for representing a real-time solution by adding spatial components to the moving objects rather than relying only on visualizing or sensor-based applications. By detecting the object in the real-time with no latency and visualizing it on a GIS map or BIM, the user will have awareness and predictive vision that help to make a better decision.

The proposed solution should be able to notify motor vehicle operators to nearby cyclists as well as their relative positions accurately by incorporating both GPS and radio signal's time of arrival, enhanced accuracy and delay avoidance will be achieved using local stations that work on monitoring cars as well as broadcasting and notifying drivers to nearby cyclists in real-time. The solution will include a bicycle tracking device that enables the local stations to pinpoint the location of the cyclist. The "brain" of the solution will be the GCITY Cloud platform that's used to illustrate the location of the cyclist as well as enhancing the selectivity of the moving vehicles as well as playing a role in communication between different subsystems. It can be argued that the development of GCITY solution will not only bring a new solution or improvements for existing systems, but a comprehensive conceptual model is seen to be an important contribution for introducing BIM and GIS with their network solutions in the warning systems for vehicle and bicycle. Another conceptual model is aimed to be developed by the BIM involvement as an indoor navigation system in the targeted streets.

\section{CONCLUSION AND FUTURE PERSPECTIVES}

The proposed solution does not only contribute to reducing the probability and severity of accidents involving cyclists as well as motor vehicles, but also it succeeds it uses an unexplored approach to the problem. There are currently numerous solutions to this problem employing technologies such as sonar radars, computer vision and lidar, however these methods are effective they are only available to a selection of high-end expensive vehicles and lack the consistency and the synergy between different automotive manufacturers that this solution proposes.

Another drawback to using previously mentioned vision-based systems is their vulnerability to weather conditions, as you well know snowfall in Nordic countries in general and in Sweden specifically can pose a great effect risk on visibility causing such systems to malfunction or stop working entirely. And even if complementary sensors such as sonar or radars were used to make up for possible faults, the system might fall short of preventing a collision due to unforeseen circumstances that affect the sensor's line of sight (e. g. obstacles, blind corners, etc.).

In contrast our proposed solution is not affected by weather conditions or other sight hindering circumstances due to the fact that it relies not on vision or sonic waves but on measuring the time of flight (TOF) of low energy radio technology by doing so we can deduce the distance between the vehicle and a number of predefined points hence calculating the vehicle's location.

In addition to the previous points our solution would be the first of its kind to employ BIM-GIS integration, indoor navigation concepts as well as the GIS network analyst that enable us to enhance the selectivity of the moving objects.

\section{ACKNOWLEDGEMENTS}

The research under the concept study was financially supported by the Sweden's innovation agency (VINNOVA). It is the Swedish government agency that administers state funding for research and development. The extension for the project is also applied to VINNOVA.

\section{REFERENCES}

Daimler, 2021. Innovation at Daimler. [last accessed on 202107-12 from: http://www.daimler.com/en/].

El Mekawy, M., Östman, A., 2010. Semantic Mapping: an Ontology Engineering Method for Integrating Building Models in IFC and CITYGML. Proceedings of the 3rd ISDE Digital Earth Summit.

El Mekawy, M., Östman, A. \& hijazi, I., 2012a. A unified building model for 3D urban GIS. ISPRS International Journal of Geo-Information, Vol. 1, No. 2, pp. 120-145.

El Mekawy, M., Östman, A. \& hijazi, I., 2012b. An evaluation of IFC-CityGML unidirectional conversion. International Journal of Advanced Computer Science \& Applications, Vol. 1, No. 3, pp. 159-171.

European Commission. INSPIRE Directive; Available online: https://inspire.ec.europa.eu/inspire-

directive/2\#: :text=The $\% 20$ INSPIRE $\% 20$ Directive $\% 2 \mathrm{C} \% 20$ est ablishing\%20an,into\%20force\%20in\%20May\%202007 (last accessed on 2021-07-12).

Fosu, R.; Suprabhas, K.; Rathore, Z.; Cory, C., 2015. Integration of Building Information Modeling (BIM) and Geographic Information Systems (GIS) - A literature review and future needs. In Proceedings of the 32nd CIB W78 Conference, Eindhoven, The Netherlands, 27-29 October.

Horizon 2020, 2021. Innovation and Networks Executive Agency, Smart Cities \& Communities. [last accessed on 202107-12 from: https://ec.europa.eu/inea/en/horizon-2020/smartcities-communities].

Hacherouf, M., Nait-Bahloul, S., Cruz, C., 2019. Transforming XML schemas into OWL ontologies using formal concept analysis. Software and Systems Modeling, Vol. 18, No. 3, pp. 2093-2110.

Hijazi, I., Ehlers, M. \& Zlatanova, S., 2012. NIBU: a new approach to representing and analysing interior utility networks 
within 3D geo-information systems. International Journal of Digital Earth, Vol. 5, No. 1, pp. 22-42.

Hijazi I, Donaubauer A, Kolbe TH., 2018. BIM-GIS Integration as Dedicated and Independent Course for Geoinformatics Students: Merits, Challenges, and Ways Forward. ISPRS International Journal of Geo-Information, Vol. 7, No. 8, pp. 319-330.

Hijazi, I.; Donaubauer, A., 2017. Integration of Building and Urban Information Modeling-Opportunities and integration approaches. In Geoinformationssysteme; Kolbe, T.H., Bill, R., Donaubauer, A., Eds.;Wichmann Verlag: Munchen, Germany, 2017; pp. 42-56, ISBN 978-3879076260.

Hor, A.-H., Sohn, G., Claudio, P., Jadidi, M., Afnan, A., 2018. A semantic graph database for BIM-GIS integrated information model for an intelligent urban mobility web application. ISPRS Annals of the Photogrammetry, Remote Sensing and Spatial Information Sciences, Vol. 4, No. 4, pp. 89-96.

IfcExplorer, 2011-2021 IfcExplorer CityGML Export; Available online: http://www.ifcwiki.org/index.php/IfcExplorer_CityGML_Expor $\mathrm{t}$ (last accessed on 2021-07-12).

Isikdag, S. and Zlatanova, S., 2009. Towards defining a framework for automatic generation of buildings in CityGML using BIM, in Lee and Zlatanova (eds.), 3D geo-information sciences, LNG\&C, Springer Verlag, pp. 79-96.

Jaguar Land Rover, 2021. Bicycle and Motorcycle Warning System. [last accessed on 2021-07-12 from: https://www.jaguar.co.uk/incontrol/driver-safety-andassistance/driving-assistance.html].

Kang, T. \& Hong, C., 2015. A study on software architecture for effective BIM/GIS-based facility management data integration. In: Automation in Construction, Vol. 54, pp. 25-38

Karan, E. P., Irizarry, J., Haymaker, J., 2016. BIM and GIS Integration and Interoperability Based on Semantic Web Technology. Journal of Computing in Civil Engineering, Vol. 30, No. 3.

Liu, X., Liu, R., Wright, G., Cheng, J., Wang, X., Li, X., 2017. A State-of-the-Art Review on the Integration of Building Information Modeling (BIM) and Geographic Information System (GIS). ISPRS International Journal of Geo-Information, Vol. 6, No. 2, p. 53.

Mercedez-Benz, 2021. Vigilant driving. [last accessed on 202107-12 from: https://www.mercedes-benz.com/en/mercedesbenz/innovation/on-the-radar-screen-recognising-risksautomatically/].

Mignard, C. \& Nicolle, C., 2014. Merging BIM and GIS using ontologies application to urban facility management in ACTIVe3D. In: Computers in Industry, Vol. 65, No. 9, pp. 1276-1290.

Nagel, C., 2007. Conversion of IFC to CityGML; Meeting of the OGC 3DIM Working Group at OGC TC/PC Meeting, Paris (Frankreich), July 2007.
Nagel, C., Stadler, A. and Kolbe, T., 2009. Conceptual Requirements for the Automatic Reconstruction of Building Information Models from Uninterpreted 3D Models, Academic Track of Geoweb 2009 Conference, Vancouver.

Safe Software, 2011-2021. FME Desktop Translator/Converter Software; Available online: https://www.safe.com/fme/fmedesktop/ (last accessed on 2021-07-12).

Stadler, A., Kolbe, T., 2007. Spatio-Semantic Coherence in the Integration of 3D City Models. In Proceedings of 5th International ISPRS Symposium on Spatial Data Quality ISSDQ, Enschede, The Netherlands, 13-15 June.

Song, Y., Wang, X., Tan, Y., Wu, P., Sutrisna, M., Cheng, J. C., Hampson, K., 2017. Trends and opportunities of BIM-GIS integration in the architecture, engineering and construction industry: A review from a spatio-temporal statistical perspective, ISPRS International Journal of Geo-Information, Vol. 6, No. 12, pp. 1-32.

Van Berlo, L., 2009. CityGML extension for Building Information Modelling (BIM) and IFC. Free and Open Source Software for Geospatial (FOSS4G), Sydney.

Van Berlo, L. and De Laat, R., 2011. Integration of BIM and GIS: The Development of the CityGML GeoBIM Extension. 3D GeoInfo Conference, Berlin, Germany, Lecture Notes in Geoinformation and Cartography Series (Springer-Verlag, Heidelberg).

Volvo, 2021. Collision warning system - detection of cyclists. [last accessed on 2021-07-12 from: https://www.volvocars.com/uk/support].

Wang, H., Pan, Y., Luo, X., 2019. Integration of BIM and GIS in sustainable built environment: A review and bibliometric analysis. Automation in Construction, 103(March), pp. 41-52.

Zhu, J., Wright, G., Wang, J., Wang, X., 2018. A Critical Review of the Integration of Geographic Information System and Building Information Modelling at the Data Level. ISPRS International Journal of Geo-Information. Vol. 7, p. 319. 